\title{
INVESTIGATION ON MATERIAL DEGRADATION OF ALLOY 617 IN HIGH TEMPERATURE IMPURE HELIUM COOLANT
}

\author{
DONG-JIN KIM*, GYEONG-GEUN LEE, SU JIN JEONG, WOO GON KIM, and JI YEON PARK \\ Nuclear Materials Division, Korea Atomic Energy Research Institute (KAERI) \\ Yuseong, Daejeon, Republic of Korea, 305-600 \\ ${ }^{*}$ Corresponding author. E-mail : djink@kaeri.re.kr \\ Received February 28, 2011 \\ Accepted for Publication April 11, 2011
}

The corrosion of materials exposed to high temperature helium in a very high temperature reactor is caused by interaction with the impurities in the helium. This interaction then induces high temperature mechanical deterioration. By considering the effect of the impurity concentration on material corrosion, a long-term coolant chemistry guideline can be determined for the range of impurity concentration at which the material is stable for a long time. In this work, surface reactions were investigated by analyzing the thermodynamics and the experimental results for Alloy 617 exposed to controlled impure helium at $950^{\circ} \mathrm{C}$. Moreover, the surfaces were examined for the Alloy 617 crept in air and in uncontrolled helium, which was explained by possible surface reactions.

KEYWORDS : Impure Helium, VHTR, Corrosion, Thermodynamics, Surface Reaction

\section{INTRODUCTION}

Helium is used as a coolant in a very high temperature reactor (VHTR) among generation IV nuclear power plants due to its high thermal conductivity, inertness, and low neutron absorption. However, helium inevitably includes impurities that create an imbalance in the surface reactivity at the interface of the coolant and the exposed materials.

The carbon monoxide, methane, hydrogen, and water that are formed by the reaction with the graphite in the core induce various surface reactions that lead to material property changes with time [1]. The compositional changes of these impurities also change the surface reactions that are possible on the material exposed to an impure helium environment.

Impurities at very low levels facilitate the material properties at only very high temperatures of above $850^{\circ} \mathrm{C}$ because the surface reactions are thermally activated processes. Therefore, the surface reactions of the materials in an intermediate heat exchanger (IHX) and the reactor core, which are exposed to very high temperature helium, should receive particular attention.

Stable oxidation prevents material degradation, internal oxidation lessens mechanical resistance, carburization embrittles material, and decarburization weakens materials [2]. Moreover, even though the surface oxide is protective, the spallation of the oxide can threaten the long-term integrity of the coolant system during the long-term operation of nuclear power plants.

A consideration of the thermodynamics shows which reactions occur on the surface of materials among oxidation, carburization, and decarburization, but it does not offer us any kinetic preference. This kinetic preference can induce localized corrosion, kinetic irreversibility, and long-term material instability, all of which lead to unexpected material degradation.

Therefore, finding the range of impurity concentration at which the material is stable, based on the thermodynamics and kinetics determined by a long-term experiment will yield crucial information for a coolant chemistry guideline.

In this work, the surface reactions of Alloy 617 as a candidate for an IHX exposed to controlled impure helium at $950^{\circ} \mathrm{C}$ were investigated based on the thermodynamics and the results of a relatively short-term experiment during 10-250 hr. Moreover, the surface of the specimens crept at $950^{\circ} \mathrm{C}$ were analyzed as functions of the exposed environments (air or uncontrolled helium).

\section{METHOD}

Table 1 shows the chemical composition of Alloy 617. Alloy 617 strengthened by a Mo and Co solid solution is known as the most promising IHX material because it has the most creep resistance [1]. A gas composition of 
$\mathrm{H}_{2} 20 \mathrm{~Pa}, \mathrm{H}_{2} \mathrm{O} 0.5 \mathrm{~Pa}, \mathrm{CH}_{4} 2 \mathrm{~Pa}$, and $\mathrm{CO} 5 \mathrm{~Pa}$ was used, based on previous reports [1-5].

Thermodynamic data and calculation of the reactions were obtained from HSC 6.0 [6].

Alloy 617 of $10 \mathrm{~mm} \times 10 \mathrm{~mm} \times 1 \mathrm{~mm}$ was tested in impure helium of $\mathrm{H}_{2} 20 \mathrm{~Pa}, \mathrm{CH}_{4} 2 \mathrm{~Pa}, \mathrm{CO} 5 \mathrm{~Pa}$, and $\mathrm{H}_{2} \mathrm{O}$ below $0.1 \mathrm{~Pa}$ at $950^{\circ} \mathrm{C}$ for $10-250 \mathrm{hr}$ with a flow rate of $50 \mathrm{cc} / \mathrm{min}$. The cross section of the test specimen was examined using back-scattered electron microscopy (BSEM) equipped with energy dispersive X-ray spectroscopy (EDS).
For specimens crept at $950^{\circ} \mathrm{C}$ in air and uncontrolled helium $\left(\mathrm{O}_{2}<1 \mathrm{ppm}, \mathrm{H}_{2} \mathrm{O}<1 \mathrm{ppm}\right)$, the cross sections near the gauge section were analyzed using SEM.

\section{RESULTS AND DISCUSSION}

Fig. 1 shows (a) a three-dimensional SEM micrograph obtained for the planes of the as-received Alloy 617 parallel and normal to the rolling direction (RD) and (b)

Table 1. Chemical Composition of Alloy 617.

\begin{tabular}{c|c|c|c|c|c|c|c|c|c|c|c|c|c|c}
\hline & \multicolumn{10}{c}{ Chemical Analysis } \\
\cline { 2 - 32 } & $\mathrm{C}$ & $\mathrm{Mn}$ & $\mathrm{Fe}$ & $\mathrm{S}$ & $\mathrm{Si}$ & $\mathrm{Cu}$ & $\mathrm{Ni}$ & $\mathrm{Cr}$ & $\mathrm{AI}$ & $\mathrm{Ti}$ & $\mathrm{Co}$ & $\mathrm{Mo}$ & $\mathrm{P}$ & $\mathrm{B}$ \\
\hline ALLOY 617 & 0.08 & 0.11 & 1.49 & 0.001 & 0.06 & 0.08 & 53.16 & 22.16 & 1.12 & 0.35 & 11.58 & 9.08 & 0.003 & 0.002 \\
\hline
\end{tabular}

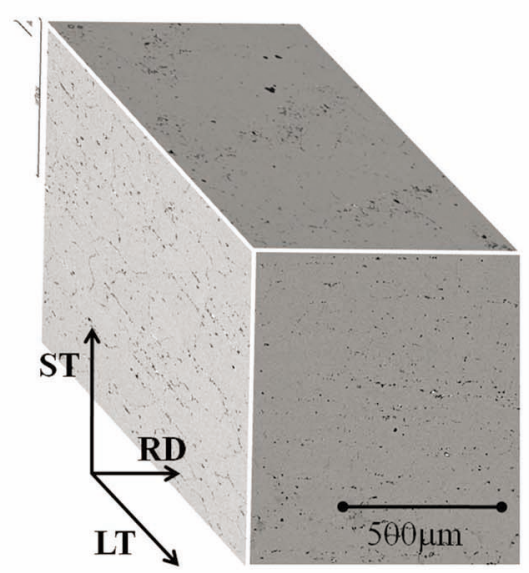

(a)

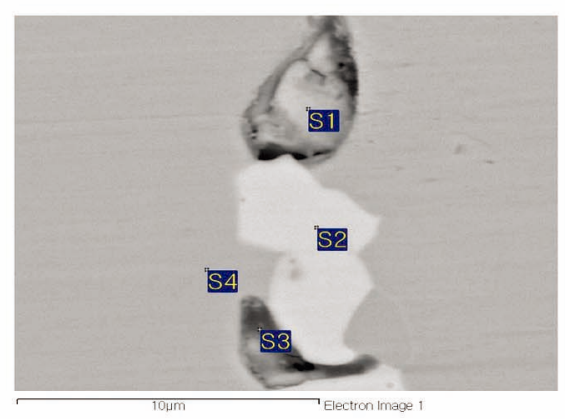

(wt\%)
\begin{tabular}{|l|l|l|l|l|l|l|l|l|l|}
\hline Spectrum & Al & Ti & Cr & Mn & Fe & Co & Ni & Mo & Remark \\
\hline S1 & 4.03 & 0.46 & 20.34 & & 1.09 & 11.50 & 51.67 & 11.12 & Matrix + other phase \\
\hline S2 & 0.42 & 0.40 & 16.57 & 0.23 & 0.37 & 7.68 & 19.83 & 54.49 & Mo rich \\
\hline S3 & 16.56 & 0.54 & 17.74 & & 1.27 & 10.20 & 47.25 & 6.48 & Matrix $+\mathrm{Ni}_{3} \mathrm{Al}$ \\
\hline S4 & 1.20 & 0.14 & 20.79 & 0.14 & 1.51 & 12.74 & 54.95 & 8.54 & Matrix \\
\hline
\end{tabular}

(b)

Fig. 1. (a) Three-dimensional SEM Micrograph and (b) EDS Results for the as-received Alloy 617. 
EDS results for particles on the Alloy 617 surface. Carbide was well developed parallel to the rolling direction. $\mathrm{A} \mathrm{Cr}$ rich phase and Mo rich phase were observed. Particles similar to $\mathrm{Ni}_{3} \mathrm{Al}$, known as the $\gamma^{\prime}$ phase [7], and other phases were observed.

Fig. 2 presents (a) the BSE image and (b) chemical composition for the SEM image for the as-received Alloy 617. Dark and bright particles identified as $\mathrm{Cr}$ rich $\mathrm{M}_{23} \mathrm{C}_{6}$ and Mo rich $\mathrm{M}_{6} \mathrm{C}$ carbides, respectively, were developed mainly at the grain boundary and partly inside the grains. Mo rich carbide looks brighter than $\mathrm{Cr}$ rich carbide in the BSE image. It seems that the surface coverage of the $\mathrm{Cr}$ rich carbide is larger than that of the Mo rich carbide.

It was previously reported that the $\mathrm{M}_{23} \mathrm{C}_{6}$ and $\mathrm{M}_{6} \mathrm{C}$ carbides are typically composed of $\mathrm{Cr}_{23-\mathrm{x}}(\mathrm{Ni}, \mathrm{Co}, \mathrm{Mo})_{\times} \mathrm{C}_{6}$ and $\mathrm{Mo}_{6-\mathrm{x}}(\mathrm{Cr}, \mathrm{Ni}, \mathrm{Co})_{\mathrm{x}} \mathrm{C}$, respectively [8], and our results were consistent with that study. According to a review article [7], $\mathrm{M}_{23} \mathrm{C}_{6}$ and $\mathrm{M}_{6} \mathrm{C}$ are thought to be the most and the second-most abundant carbide forms in Alloy 617, respectively, which was similar to the as-received Alloy 617 of this study. $\mathrm{M}_{23} \mathrm{C}_{6}$ as the main carbide form was considered for thermodynamic prediction and analysis of the experimental results in this study.

Gas/gas reaction is not considered because of the very diluted and flowing condition in which there is an extremely low collision probability. For this reason, a steady state rather than a thermodynamic equilibrium is assumed [3].

Regarding the impurities in the helium coolant of a VHTR, water and hydrogen are inevitably introduced due to outgassing, air ingress, and in-leakage. Consequently, methane and carbon monoxide are formed by reaction with graphite in the core.

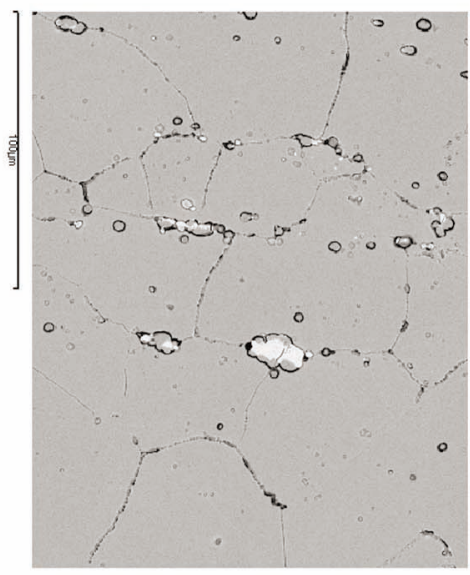

(a)

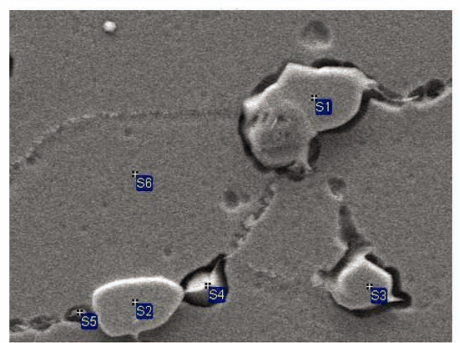

$(\mathrm{wt} \%)$

\begin{tabular}{|l|l|l|l|l|l|l|l|l|l|}
\hline Spectrum & Al & Ti & Cr & Mn & Fe & Co & Ni & Mo & Remark \\
\hline S1 & & 0.19 & 63.50 & 0.42 & 0.16 & 1.86 & 5.22 & 28.78 & Cr rich carbide \\
\hline S2 & 1.21 & 0.55 & 16.12 & 0.56 & 0.13 & 5.01 & 14.37 & 62.04 & Mo rich carbide \\
\hline S3 & 0.02 & 0.01 & 62.75 & 0.22 & 0.57 & 2.78 & 6.03 & 27.61 & Cr rich carbide \\
\hline S4 & & & 60.21 & 0.11 & 0.61 & 3.39 & 11.41 & 24.35 & Cr rich carbide \\
\hline S5 & 0.40 & 0.26 & 28.17 & 0.57 & 1.41 & 11.44 & 50.82 & 6.94 & Matrix + other phase \\
\hline S6 & 2.99 & 0.12 & 25.86 & & 1.58 & 11.09 & 47.56 & 10.82 & Matrix \\
\hline
\end{tabular}

(b)

Fig. 2. (a) BSE Image and (b) Chemical Composition for SEM Image of the as-received Alloy 617. 
Moreover, oxygen can react with graphite to form $\mathrm{CO}$. The equilibrium partial pressure of oxygen for this reaction at $950^{\circ} \mathrm{C}$ is very low at about $10^{-23} \mathrm{~atm}$. The driving force for $\mathrm{CO}$ formation is larger than $\mathrm{CO}_{2}$ formation, and the reduction of $\mathrm{CO}_{2}$ to $\mathrm{CO}$ is available, indicating that the presence of $\mathrm{CO}_{2}$ as an impurity in the helium is much less probable.

At a given gas composition $\left(\mathrm{H}_{2} 20 \mathrm{~Pa}\right.$ and $\left.\mathrm{H}_{2} \mathrm{O} 0.5 \mathrm{~Pa}\right)$, the equilibrium partial pressure of oxygen for the $\mathrm{H}_{2} \mathrm{O}$ formation reaction by the reaction with hydrogen at $950^{\circ} \mathrm{C}$ is about $10^{-19}$ atm, which is a very low value but higher than the equilibrium partial pressure of oxygen for the $\mathrm{CO}$ formation reaction. Any introduction of oxygen can cause $\mathrm{CO}$ and $\mathrm{H}_{2} \mathrm{O}$ formation depending on kinetics.

Surface reactions on the materials used in an IHX depend on the material composition, helium impurity ratio, impurity concentration, temperature, time, kinetics, etc., which affect material corrosion and, hence, material degradation. This is why surface reaction prediction and a high temperature experiment, followed by a test sample examination, need to be conducted.

Various reactions, such as oxidation, carbide decomposition, decarburization, carbide formation, and carburization can be considered for chromium by reaction with $\mathrm{H}_{2} \mathrm{O}, \mathrm{H}_{2}, \mathrm{CH}_{4}$, and $\mathrm{CO}$. Moreover, minor elements such as $\mathrm{Mn}, \mathrm{Ti}, \mathrm{Al}$, etc., should be considered for surface reactions.

It should be noted that $\mathrm{H}_{2} \mathrm{O}$ tends to oxidize/decarburize the material, methane tends to reduce/carburize the material, and carbon monoxide tends to oxidize/carburize the material. As mentioned above, stable and protective oxide can prevent material degradation in a well-balanced environment while internal oxidation and/or non-adherent oxide will lead to mechanical weakening and spallation, carburization will embrittle material, and decarburization will lessen the high temperature creep strength [2]. Therefore, a well-balanced environment should be determined and confirmed experimentally.

Fig. 3 shows the standard free energy, $\Delta \mathrm{G}^{\mathrm{o}}$ for the oxidation (oxidation 1: $\mathrm{M}+\mathrm{H}_{2} \mathrm{O}=\mathrm{MO}+\mathrm{H}_{2}$ ) of various metals composing Alloy 617 by the reaction with $\mathrm{H}_{2} \mathrm{O}$ as a function of the temperature. The positive slope and negative value at $0 \mathrm{~K}$ represent the entropy decrease, caused by a decrease in the number of moles, and the exothermic reaction of oxidation, respectively. An exothermic reaction causes a decrease of the driving force with the temperature. The oxidation power was $\mathrm{Al}>\mathrm{Ti}>\mathrm{Si}>\mathrm{Cr}>\mathrm{Mn}$. Ni and Fe do not react with $\mathrm{H}_{2} \mathrm{O}$ to be oxidized spontaneously in the impure helium condition of this study.

Fig. 4 shows the standard free energy, $\Delta G^{\text {o }}$ for the oxidation (oxidation 2: $\mathrm{M}+\mathrm{CO}=\mathrm{MO}+\mathrm{C}$ ) of various metals composing Alloy 617 by the reaction with $\mathrm{CO}$ as a function of the temperature. The driving force for oxidation 2 was larger than the driving force for oxidation 1 at the standard state. The slope was more positive, which was caused by the removal of gaseous $\mathrm{CO}$. The oxidation power was also $\mathrm{Al}>\mathrm{Ti}>\mathrm{Si}>\mathrm{Cr}>\mathrm{Mn}$.

However, the driving force for oxidation 1 of $\mathrm{Cr}$ ($37,132 \mathrm{cal} / \mathrm{mol}$ ) was larger than that for oxidation 2 of $\mathrm{Cr}$ $(-3,732 \mathrm{cal} / \mathrm{mol})$, which was unlike the results of the standard free energy and indicates that the oxidation by $\mathrm{H}_{2} \mathrm{O}$ is more favorable than the oxidation by $\mathrm{CO}$, considering gas composition and activity $\left(\mathrm{H}_{2} \mathrm{O} 0.5 \mathrm{~Pa}, \mathrm{H}_{2} 20 \mathrm{~Pa}, \mathrm{CO} 5 \mathrm{~Pa}\right.$, activity of $\mathrm{Cr} 0.72$, and activity of $\mathrm{C} 0.004)$.

$\mathrm{Cr}$ can be oxidized or reduced depending on pco around a certain $\mathrm{CO}$ concentration according to oxidation 2 while $\mathrm{Cr}$ oxidation by $\mathrm{H}_{2} \mathrm{O}$ has a much larger window. The direction of the oxidation reaction 2 by $\mathrm{CO}$ according to $\mathrm{CO}$ gas composition and the activities of the carbon and $\mathrm{Cr}$ in the solid is considered to be important. The direction of this reaction, which is called a microclimate reaction [2], is closely related to the stability of metal in impure helium. The physical size of the zone in which the processes occur is expected to be extremely small, hence the term "microclimate" [4].

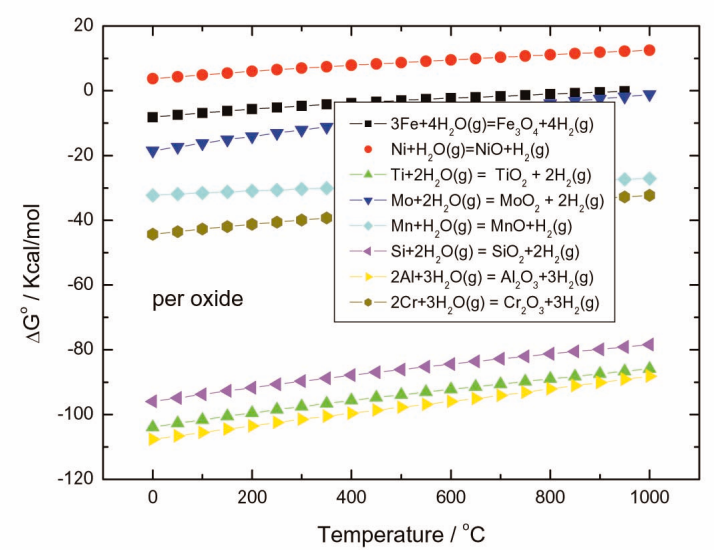

Fig. 3. Standard Free Energy, $\Delta \mathrm{G}^{\circ}$ for the Oxidation (Oxidation 1) of Various Metals Composing Alloy 617 by the Reaction with $\mathrm{H}_{2} \mathrm{O}$ as a Function of the Temperature.

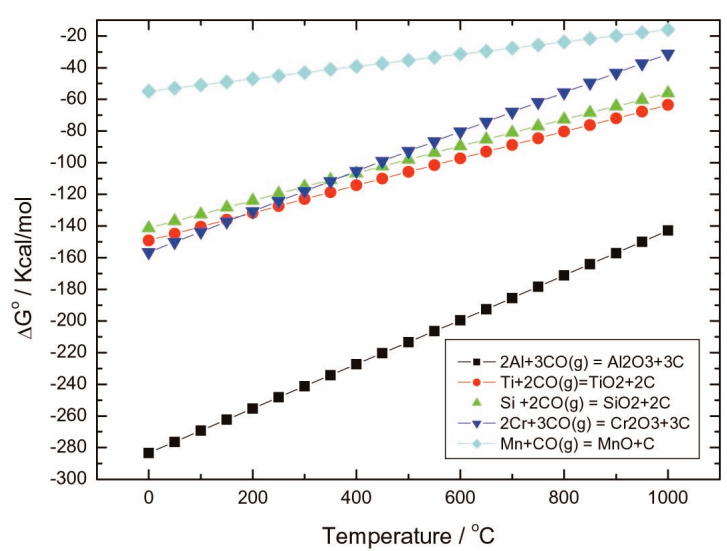

Fig. 4. Standard Free Energy, $\Delta \mathrm{G}^{\circ}$ for the Oxidation (Oxidation 2) of Various Metals Composing Alloy 617 by the Reaction with $\mathrm{CO}$ as a Function of the Temperature. 
When the CO content is lower than a critical concentration, the oxide and carbon in the alloy cannot coexist, but a backward reaction occurs to form $\mathrm{CO}$ until either the oxide or the carbon disappears without the help of any gaseous species [1]. At this time, the oxide is reduced and the carbon dissolves into materials to be embrittled locally if the $\mathrm{CH}_{4}$ content is relatively higher than the $\mathrm{H}_{2} \mathrm{O}$ content. However, metal is oxidized and decarburized to be less creep resistant if the $\mathrm{H}_{2} \mathrm{O}$ content is relatively higher than the $\mathrm{CH}_{4}$ content. The formed oxide is reduced again to form $\mathrm{CO}$, which creates the surface layer porous. Therefore, the $\mathrm{CH}_{4} / \mathrm{H}_{2} \mathrm{O}$ ratio is also important to prevent material degradation.

Fig. 5 shows the standard free energy, $\Delta G^{0}$ for decarburization of carbide-forming metals among elements composing Alloy 617 as a function of the temperature. Standard free energies, $\Delta \mathrm{G}^{\mathrm{o}}$ for the combined reaction $\left(\mathrm{MC}+\mathrm{H}_{2} \mathrm{O}=\mathrm{M}+\mathrm{CO}+\mathrm{H}_{2}\right)$ of the decarburization reaction of carbon in the matrix $\left(\mathrm{C}+\mathrm{H}_{2} \mathrm{O}=\mathrm{CO}+\mathrm{H}_{2}\right)$ and the carbide decomposition reaction were plotted together. The negative slope and positive value at $0 \mathrm{~K}$ represent the entropy increase, caused by an increase in the number of moles, and the endothermic reaction of decarburization, respectively. This decarburization reaction does not occur spontaneously in the standard state.

However, the driving forces for the decarburization reaction of the carbon in the matrix and the combined reaction of $\mathrm{Cr}_{23} \mathrm{C}_{6}$ were $-11,133$ and $-66,611 \mathrm{cal} / \mathrm{mol}$, respectively, which is unlike the results of the standard free energy and indicates that the decarburization of the carbon in the matrix and the $\mathrm{Cr}$ carbide decomposition, followed by the decarburization, are possible with gas composition and activity $\left(\mathrm{H}_{2} \mathrm{O} 0.5 \mathrm{~Pa}, \mathrm{H}_{2} 20 \mathrm{~Pa}, \mathrm{CO} 5 \mathrm{~Pa}\right.$, activity of $\mathrm{Cr} 0.72$, and activity of $\mathrm{C} 0.004$ ).

For this reaction, the carbide formation tendency should be also considered. $\mathrm{Cr}$ carbide $(\mathrm{Cr}$ carbide formation $\Delta \mathrm{G}$ $=-188 \mathrm{cal} / \mathrm{mol}$ ) can be decomposed depending on the carbon and $\mathrm{Cr}$ activities whereas the driving force for $\mathrm{TiC}$ formation $(\Delta \mathrm{G}=-13,614 \mathrm{cal} / \mathrm{mol})$ is very strong to avoid decomposition.

Fig. 6 shows the standard free energy, $\Delta \mathrm{G}^{\mathrm{o}}$ for the carburization $\left(\mathrm{CH}_{4}=\mathrm{C}+2 \mathrm{H}_{2}\right)$ and the combined reaction $\left(\mathrm{CH}_{4}+\mathrm{M}=\mathrm{MC}+2 \mathrm{H}_{2}\right)$ of the carburization reaction and the carbide formation of carbide-forming elements among metals composing Alloy 617 as a function of the temperature. The negative slope and positive value at $0 \mathrm{~K}$ for the carburization reaction $\left(\mathrm{CH}_{4}=\mathrm{C}+2 \mathrm{H}_{2}\right)$ represent the entropy increase, caused by an increase in the number of moles, and the endothermic reaction of carburization, respectively. The power for the combined reaction of the carburization reaction and the carbide formation reaction was $\mathrm{Cr}_{23} \mathrm{C}_{6}>\mathrm{TiC}>\mathrm{SiC}>\mathrm{Mo}_{2} \mathrm{C}$.

The driving forces for the carburization reaction into the matrix and the combined reaction of $\mathrm{Cr}_{23} \mathrm{C}_{6}$ were 38,914 and $-233,672 \mathrm{cal} / \mathrm{mol}$, respectively, indicating that the carburization into the matrix and the carburization, followed by the $\mathrm{Cr}$ carbide formation, are possible with gas composition and activity $\left(\mathrm{H}_{2} \mathrm{O} 0.5 \mathrm{~Pa}, \mathrm{H}_{2} 20 \mathrm{~Pa}, \mathrm{CO}\right.$ $5 \mathrm{~Pa}$, activity of $\mathrm{Cr} 0.72$ and activity of $\mathrm{C} 0.004)$. The $\mathrm{Cr}$ carbide $(\Delta \mathrm{G}=-188 \mathrm{cal} / \mathrm{mol})$ can be formed depending on the carbon and $\mathrm{Cr}$ activities.

Let us consider the oxidation 2 reaction $(\mathrm{M}+\mathrm{CO}=\mathrm{C}$ $+\mathrm{MO}$ ) during oxidation, decarburization, and carburization. According to the reaction, the equilibrium constant $\mathrm{K}=$ $\mathrm{a}_{\mathrm{M}} \cdot \mathrm{p}_{\mathrm{CO}} / \mathrm{a}_{\mathrm{C}}$, where $\mathrm{a}_{\mathrm{M}}, \mathrm{p}_{\mathrm{CO}}$, and $\mathrm{a}_{\mathrm{C}}$ represent the activity of the metal, the partial pressure of $\mathrm{CO}$, and the carbon activity, respectively.

First, during the oxidation, the $\mathrm{Cr}$ activity will decrease at the oxide/metal interface, causing an increase of $\mathrm{CO}$ equilibrium partial pressure. Second, the carbon activity will decrease, which will lead to a $\mathrm{CO}$ equilibrium partial

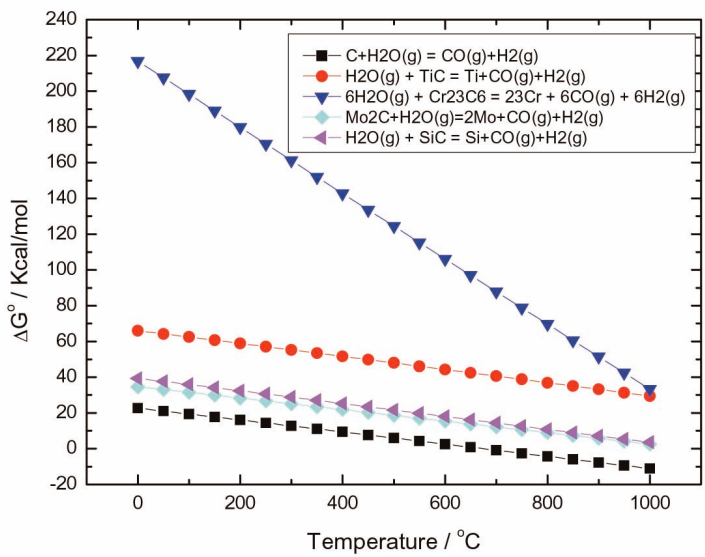

Fig. 5. Standard Free Energy, $\Delta \mathrm{G}^{\circ}$ for the Decarburization of Carbide-forming Metals Among Metals Composing Alloy 617 as a Function of the Temperature.

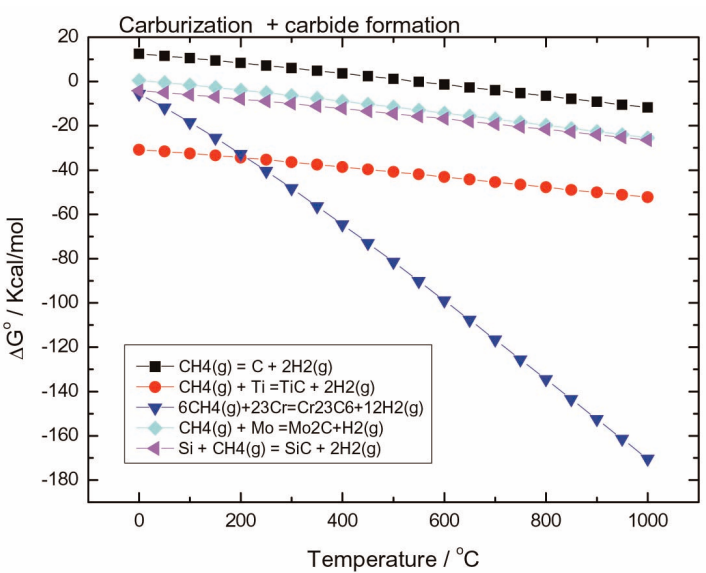

Fig. 6. Standard Free Energy, $\Delta \mathrm{G}^{\circ}$ for the Carburization $\left(\mathrm{CH}_{4}\right.$ $\left.=\mathrm{C}+2 \mathrm{H}_{2}\right)$ and the Combined Reaction $\left(\mathrm{CH}_{4}+\mathrm{M}=\mathrm{MC}+\right.$

$2 \mathrm{H}_{2}$ ) of the Carburization Reaction and the Carbide Formation $(\mathrm{M}+\mathrm{C}=\mathrm{MC})$ of Carbide-forming Metals Among Metals Composing Alloy 617 as a Function of the Temperature. 


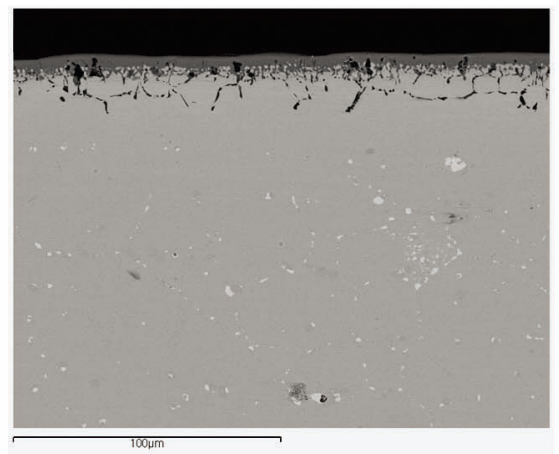

(a)

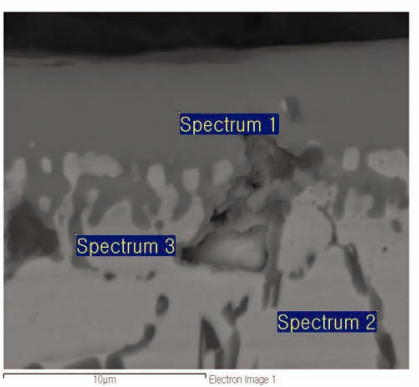

(Wt \%)
\begin{tabular}{|l|l|l|l|l|l|l|l|l|l|l|}
\hline Spectrum & O & Al & Ti & Cr & Mn & Fe & Co & Ni & Mo & Remark \\
\hline Spectrum 1 & 23.57 & 0.23 & 1.20 & 73.85 & & 0.19 & 0.15 & 0.64 & 0.22 & Cr oxide \\
\hline Spectrum 2 & 11.96 & 19.65 & 0.03 & 11.21 & & 1.41 & 8.75 & 40.40 & 6.62 & Al oxide \\
\hline Spectrum 3 & 15.97 & 10.92 & 0.91 & 35.33 & & 1.11 & 5.69 & 25.89 & 4.31 & $\begin{array}{l}\text { Al oxide, } \\
\text { Cr oxide }\end{array}$ \\
\hline
\end{tabular}

(b)

Fig. 7. (a) BSE Image for the Cross Section and (b) EDS Results of 250-hr Tested Alloy 617 in a Controlled Impure Helium Environment at $950^{\circ} \mathrm{C}$.

pressure decrease and carbide decomposition during the decarburization. Finally, carburization induces a carbon activity increase with time, which causes a $\mathrm{p}_{\mathrm{CO}}$ increase and carbide formation. Activity and partial pressure change with time according to the microclimate reaction and indicate that determining the protective range of $\mathrm{p}_{\mathrm{CO}}$ rather than finding a deterministic $\mathrm{p}_{\mathrm{CO}}$ is a key to prevent a material from degradation.

Moreover, the carbide stabilizing element Mo and $\mathrm{Mo}_{6} \mathrm{C}$ formation will also decrease carbon activity and lead to a $\mathrm{p}_{\mathrm{CO}}$ increase. Carbide formation and the oxidation of minor elements will affect the $\mathrm{p}_{\mathrm{CO}}, \mathrm{p}_{\mathrm{O} 2}$ and $\mathrm{a}_{\mathrm{c}}$. According to previous reports [3-5], carbon and $\mathrm{Cr}$ activities are not unique values but $0.0015-0.004$ and $0.35-0.77$, respectively. Uncertainty of the carbon activity and $\mathrm{Cr}$ activity will change CO partial pressure. Consequently, an optimum range of gas composition in the operating temperature range should be found based on thermodynamic prediction and experimental results.

Fig. 7 shows (a) a BSE image and (b) EDS results for the cross section after $250 \mathrm{hr}$ of experimentation under the controlled impure helium environment at $950^{\circ} \mathrm{C}$. The chromium oxide formed on the surface and the aluminium oxidized along the grain boundary in the internal direction. Carbide that is spread out widely along the grain boundary on the cross section of the as-received Alloy 617 was not observed near the surface. This carbide can be seen again beneath this decarburized layer. These results are consistent with other reports $[1,5,9]$.

According to the thermodynamic prediction, the driving force of $\mathrm{Al}$ for oxidation was the largest among the alloying elements, and only $\mathrm{Cr}$ among the major alloying elements can be oxidized. Therefore, Al at a low level in the alloy can be oxidized at a very low oxygen partial pressure internally and preferentially along the open structured grain boundary, and $\mathrm{Cr}$ forms the surface oxide layer, as shown in Fig. 7. However, significant amounts of $\mathrm{Mn}, \mathrm{Si}$, and $\mathrm{Ti}$ were not detected in the oxide even though the oxidation of these metals is possible thermodynamically.

Decarburization following the $\mathrm{Cr}$ carbide decomposition is also possible according to thermodynamic prediction. The carbide decomposition reaction can be accelerated by $\mathrm{Cr}$ oxidation, which induces a $\mathrm{Cr}$ activity decrease. 


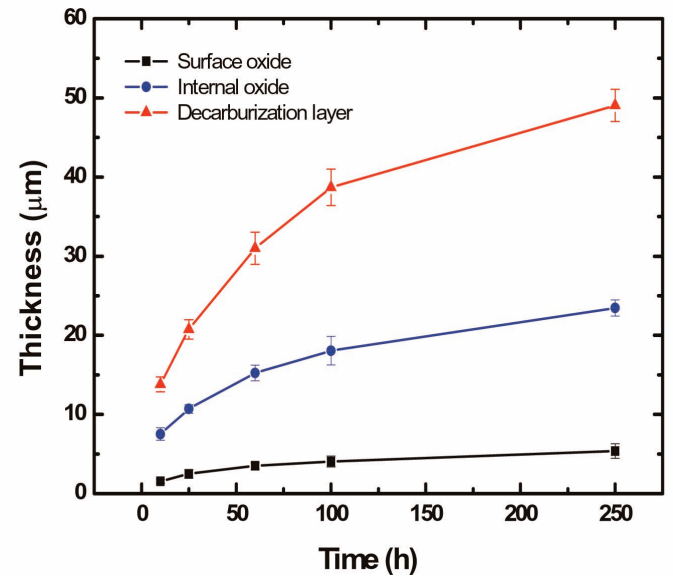

Fig. 8. Surface Oxide, Internal Oxide, and Decarburization Layer Thickness for Alloy 617 as a Function of the Test Duration in a Controlled Impure Helium Environment at $950^{\circ} \mathrm{C}$.

However, carburization was not observed. The protective oxide seems to play a role as the effective barrier for carburization.

Fig. 8 presents the surface oxide, internal oxide, and decarburization layer thickness for Alloy 617 as a function of the test duration in the controlled impure helium environment at $950^{\circ} \mathrm{C}$. The thickness of the surface oxide, internal oxide, and decarburization layer increased with the test time, indicating that the surface reaction occurs continuously. However, the increase rate of the thickness decreased with time. This means that the surface oxide is protective in effectively preventing further surface reaction. The thickness would increase linearly with time if the surface layer were not protective but porous.

Considering that the decarburization is triggered by the surface oxidation causing a $\mathrm{Cr}$ activity decrease and, hence, carbide decomposition, the decarburization layer thickness varies with the surface oxide thickness. It should be noted that carburization did not occur in the test, which indicates the role of the protective layer.

It was reported [10] that creep resistance is lower in uncontrolled helium $\left(\mathrm{O}_{2}<1 \mathrm{ppm}, \mathrm{H}_{2} \mathrm{O}<1 \mathrm{ppm}\right)$ than in an air environment at $950^{\circ} \mathrm{C}$. One would expect that this behavior is related to the different surface reaction behaviors between uncontrolled helium and air.

Let us consider thermodynamics. The oxygen partial pressures of uncontrolled helium and air are about $10^{-6}$ atm and $0.2 \mathrm{~atm}$, respectively. Assuming that $\mathrm{p}_{\mathrm{CO}}$ and $\mathrm{p}_{\mathrm{H} 2 \mathrm{O}}$ are $10^{-7}$ and $10^{-6} \mathrm{~atm}$, respectively, in helium, the hydrogen partial pressure is about $2 \times 10^{-11} \mathrm{~atm}$.

According to the thermodynamic calculation, the driving forces for oxidation and decarburization reactions ( $\Delta \mathrm{G}=-187,448$ and $-152,682 \mathrm{cal} / \mathrm{mol}$, respectively) in air are higher than those $(\Delta \mathrm{G}=-142,955$ and $-123,020$ $\mathrm{cal} / \mathrm{mol}$, respectively) in the above helium environment. Carburization is not possible in the absence of methane

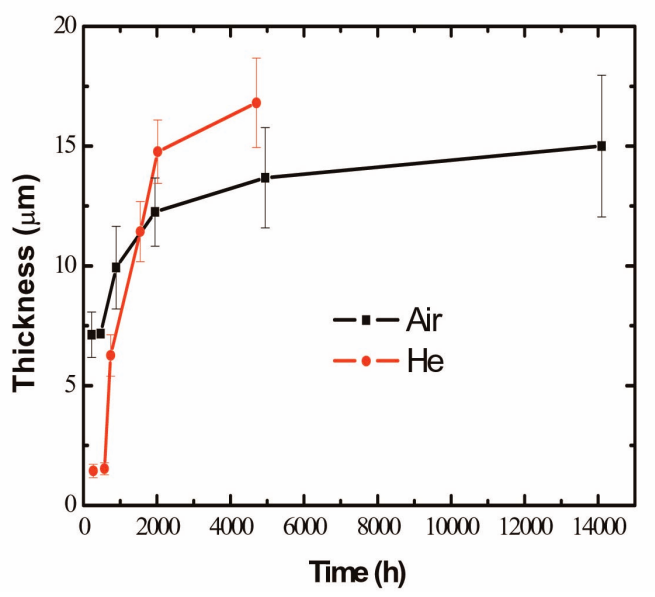

Fig. 9. Surface Oxide Thickness as a Function of the Exposure Time for the Creep test at $950^{\circ} \mathrm{C}$ in Uncontrolled Helium and Air.

and with a low amount of carbon monoxide. This indicates that both oxidation and decarburization reactions are preferable in air. Moreover, since CO content is very low, oxide and carbon in the alloy cannot coexist until either the oxide or carbon disappears without the help of any gaseous species, leading to material degradation, as mentioned above.

Fig. 9 shows the surface oxide thickness as a function of the exposure time for the creep test at $950^{\circ} \mathrm{C}$ in uncontrolled helium and air. The oxide thickness increased slowly with the duration of time to attain a steady state thickness.

The oxide thickness was higher and increased rapidly with time in helium where the driving force for oxidation was smaller. The passivity of the surface oxide in air may be different from the passivity of that in helium. We think that the surface oxide formed in air is more protective in effectively preventing further surface reaction.

Fig. 10 is the decarburized layer thickness as a function of the exposure time for the creep test at $950^{\circ} \mathrm{C}$ in uncontrolled helium and air. The decarburized layer thickness was higher in helium. The thicker oxide formation induces a greater chromium activity decrease in helium, which accelerates the carbide decomposition and thickens the decarburized layer. It was reported [11] that a material containing grain boundary carbides has higher creep strength than a carbide-free material. The grain boundary carbide suppresses creep deformation, such as grain boundary sliding and reduces the agglomeration of voids. In this regard, the specimen that was tested in the uncontrolled helium and had a thicker decarburized layer is less creep resistant than the specimen that was tested in air and had a thinner decarburized layer. The microstructural changes caused by the surface reaction significantly affected the creep property, which indicates that determining a well-balanced environment is very 


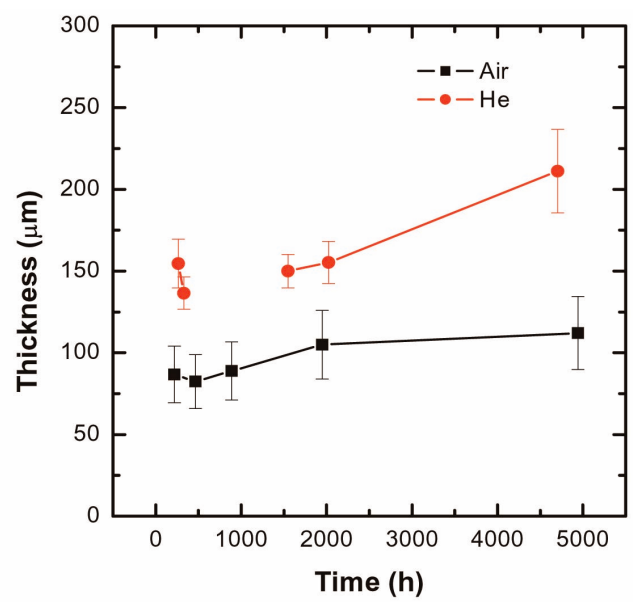

Fig. 10. Decarburized Layer Thickness as a Function of the Exposure Time for the Creep Test at $950^{\circ} \mathrm{C}$ in Uncontrolled Helium and Air.

important for the material integrity in impure helium at high temperature.

Differences in the microstructure caused by differences in the surface reaction behaviors between air and uncontrolled helium will be more obvious with time and varying temperature because the surface reaction is a thermally-activated time-dependent process. Thus, a comparison between the data for the creep tests when a low stress was applied in air and helium, i.e., the data for the long-time domain is much more meaningful. The data of the short-time domain can be complicated due to the combined effect of high applied stress.

\section{SUMMARY}

The driving forces for many surface reactions on Alloy 617 were compared. Possibilities of oxidation, decarburization, and carburization reactions depend on the impurity concentration in the helium and activities of the alloying elements. Our study suggests that material degradation can be minimized by a stable and protective oxide formed in a well-balanced environment to avoid severe carburization, decarburization, spallation, and so on.

The surface was examined for a specimen tested at $950^{\circ} \mathrm{C}$ in a controlled helium environment. The thickness of the surface oxide, internal oxide, and decarburization layer increased with the test time. However, the increase rate of the thickness decreased with time, indicating that the surface oxide formed during the test is protective in preventing further surface reaction. Decarburization is facilitated by the surface oxidation that causes a $\mathrm{Cr}$ activity decrease and, hence, carbide decomposition. Carburization did not occur in the test, indicating that the surface oxide is protective enough to prevent the carburization reaction.

Examination of the specimen crept at $950^{\circ} \mathrm{C}$ revealed that the oxide thickness was higher and increased rapidly with the time in helium. This indicates that the oxide formed in air is more passive. The thicker oxide formation induced a thicker decarburized layer. The more severe decarburizing tendency of grain boundary carbide led to a lower creep resistance in uncontrolled helium than in an air environment. The experimental results were explained fairly well in view of the thermodynamic considerations.

\section{ACKNOWLEDGEMENT}

This work was supported by the National Research Foundation of Korea (NRF) grant funded by the Korea government (MEST) (No. 2010-0029810).

\section{REFERENCES}

[ 1 ] C. Cabet, F. Rouillard, J. Nuclear Materials, 392 (2009) 235.

[2] K.G.E. Brenner, L.W. Graham, Nucl. Technol. 66 (1984) 404.

[3] W.J. Quadakkers, Werkstoffe und Korrosion, 36 (1985) 335.

[4] M. R. Warren, High Temperature Technology, 4 (1986) 119.

[5 ] C. Cabet, J. Chapovaloff, F. Rouillard, G. Girardin, D. Kaczorowski, K. Wolski, M. Pijolat, J. Nuclear Materials, 375 (2008) 173.

[6] HSC Chemistry, 6.0.

[7] W. Ren, R. Swimdeman, J. Pressure Vessel Technology, 131 (2009) 024002-1.

[8] T. S. Jo, J. H. Lim, Y. D. Kim, J. Nuclear Materials, 406 (2010) 360 .

[9] T. S. Jo, S. Lee, G.-S. Kim, S.-H. Kim, Y. D. Kim, Kor. J. Mater. Res., 17 (2007) 268.

[10] W. G. Kim, S. N. Yin, G.-G. Lee, Y. W. Kim, p. 243, proceeding of Transactions of the Korean Nuclear Society Autumn Meeting, Gyeongju, Korea, 29-30 October, 2009.

[11] S. Kihara, J. B. Newkirk, A. Ohtomo, Y. Saiga, Metallurgical Transactions A, 11A (1980) 1019. 